\title{
Patterns and correlates of cannabis use among individuals with HIV/AIDS in Maritime Canada
}

\author{
Gregory E Harris MSc PhD ${ }^{1}$, Lise Dupuis RN BScN² , Gerald J Mugford PhD CMH ${ }^{3}$, Lynn Johnston $\mathrm{MD}^{4}$, \\ David Haase MBBS ${ }^{5}$, Ginny Page RN ${ }^{6}$, Heather Haldane RN ${ }^{7}$, Nicholas Harris MA PhD(c) ${ }^{8}$, \\ William K Midodzi PhD ${ }^{9}$, Gordon Dow $\mathrm{MD}^{10}$
}

GE Harris, L Dupuis, GJ Mugford, et al. Patterns and correlates of cannabis use among individuals with HIV/AIDS in Maritime Canada. Can J Infect Dis Med Microbiol 2014;25(1):e1-e7.

BACKGROUND: The prevalence of cannabis use in HIV-infected individuals is high and its long-term effects are unclear.

METHODS: The prevalence, perceived benefits and consequences, and predictors of cannabis use were studied using a cross-sectional survey in two immunodeficiency clinics in Maritime Canada.

RESULTS: Current cannabis use was identified in 38.5\% (87 of 226) of participants. Almost all cannabis users (85 of 87 [97.7\%]) acknowledged its use for recreational purposes, with $21.8 \%$ (19 of 87 ) reporting medicinal cannabis use. The majority of patients enrolled in the present study reported mild or no symptoms related to HIV $(n=179)$. Overall, $80.5 \%$ (70 of 87) of the cannabis-using participants reported a symptomrelieving benefit, mostly for relief of stress, anorexia or pain. Participants consumed a mean $( \pm$ SD) of $18.3 \pm 21.1 \mathrm{~g}$ of cannabis per month and spent an average of $\$ 105.15 \pm 109.87$ on cannabis per month. Cannabis use was associated with rural residence, lower income level, driving under the influence of a substance, and consumption of ecstasy and tobacco. Income level, ecstasy use and tobacco use were retained as significant predictors in regression modelling. Cannabis use was not associated with adverse psychological outcomes.

DISCUSSION: Prolonged previous cannabis consumption and the substantial overlap between recreational and medicinal cannabis use highlight the challenges in obtaining a tenable definition of medicinal cannabis therapy.

Key Words: Cannabis; High-risk behaviour; HIVIAIDS

\section{Les modes et les corrélats de consommation de cannabis chez des personnes atteintes du VIH-sida dans les Maritimes, au Canada}

HISTORIQUE : La prévalence de consommation de cannabis est élevée chez les personnes infectées par le VIH, mais on n'en connaît pas les effets à long terme.

MÉTHODOLOGIE : Les chercheurs ont étudié la prévalence, les avantages perçus et les conséquences et prédicteurs de consommation de cannabis au moyen d'un sondage transversal mené dans deux cliniques d'immunodéficience des Maritimes, au Canada.

RÉSULTATS : Les chercheurs ont constaté une consommation courante de cannabis chez $38,5 \%$ des participants (87 sur 226). Presque tous les consommateurs de cannabis (85 sur 87 [97,7 \%]) admettaient en prendre pour des fins récréatives, et 21,8 \% (19 sur 87) indiquaient en prendre pour des fins médicinales. La majorité des patients qui participaient à la présente étude a déclaré des symptômes du VIH légers, sinon inexistants $(\mathrm{n}=179)$. Dans l'ensemble, 80,5\% des participants consommateurs de cannabis (70 sur 87 ) ont affirmé remarquer un soulagement des symptômes, particulièrement le stress, l'anorexie ou la douleur. Les participants consommaient en moyenne $18,3 \pm 21,1 \mathrm{~g}$ de cannabis par mois et dépensaient en moyenne $105,15 \pm 109,87 \$$ par mois pour se le procurer. La consommation de cannabis était liée à un logement en milieu rural, à un niveau de revenu plus bas, à la conduite sous l'influence d'une substance et à la consommation d'ecstasy et de tabac. Le niveau de revenu, la consommation d'ecstasy et la consommation de tabac étaient considérés comme des prédicteurs importants selon le modèle de régression. La consommation de cannabis ne s'associait pas à des résultats psychologiques indésirables.

EXPOSÉ : Une consommation antérieure prolongée de cannabis et le chevauchement important entre la consommation de cannabis à des fins récréatives et médicinales font ressortir la difficulté d'obtenir une définition viable du traitement médicinal par le cannabis.

The major active ingredient in cannabis is $\Delta$-9-tetrahydrocannibinol. More than 80 other phytocannabinoids have been identified in $\mathrm{C}$ sativa in addition to $\Delta-9$-tetrahydrocannibinol (5). Synthetic cannabinoids refer to those that have been manmade. Three prescribed cannabinoids can be obtained in Canada: a synthetic $\Delta$-9-tetrahydrocannabinol (dronabinol), marketed as Marinol (Unimed Pharmaceuticals, USA) for HIV-associated anorexia and chemotherapy-induced nausea and vomiting; a synthetic $\Delta$-9-tetrahydrocannabinol (nabilone), marketed as Cesamet (Valeant Canada LP, Canada) for chemotherapy-induced nausea and vomiting; and a herbal extract oromucosal spray, marketed as Sativex (GW Pharmaceuticals, United Kingdom) for neuropathic pain in multiple sclerosis. although this was not the principal reason for its reported use.

${ }^{1}$ Faculty of Education, Memorial University of Newfoundland, St John's, Newfoundland and Labrador; ${ }^{2}$ Horizon Health Network, Moncton, New Brunswick; ${ }^{3}$ The Health Sciences Centre, Faculty of Medicine (Medicine and Psychiatry), St John's, Newfoundland and Labrador;

${ }^{4}$ Department of Medicine, Faculty of Medicine, Capital District Health Authority; ${ }^{5}$ Capital District Health Authority and Dalhousie University; ${ }^{6}$ QEII Health Sciences Centre, Victoria General Hospital Site; ${ }^{7}$ Department of Infectious Diseases, Center for Clinical Research, Halifax, Nova Scotia; ${ }^{8}$ Lakehead University, Thunder Bay, Ontario; ${ }^{9}$ Faculty of Medicine, Memorial University, St John's, Newfoundland and Labrador; ${ }^{10}$ Dalhousie University, The Moncton Hospital, Moncton, New Brunswick

Correspondence: Dr Gregory E Harris, Faculty of Education, GA Hickman Building, Memorial University of Newfoundland, PO Box 4200 , St John's, Newfoundland and Labrador A1B 3X8. Telephone 709-864-6925, fax 709-864-2345, e-mail gharris@mun.ca 
Access to nonprescription herbal cannabis was authorized for medical purposes in Canada through the Marijuana Medical Access Regulations in 2001 (6). There were approximately 5000 medicinal cannabis users registered through Health Canada in 2010 (7). Despite the existence of four potential sources of medicinal cannabis, the majority of medicinal cannabis users living with HIV/AIDS in Canada use smoked herbal cannabis obtained from illegal sources $(8,9)$. This raises important questions regarding patient preference of, and access to, herbal cannabis and pharmaceutical alternatives.

The use of cannabinoids as therapeutic agents has generated a significant amount of controversy. A detailed review of studies regarding prescribed oral medicinal cannabinoids has suggested that there is an increased risk of nonserious adverse events, but that the risks of longterm exposure have not been characterized (10). There is a growing body of scientific literature highlighting serious adverse consequences associated with recreational cannabis use including psychiatric illness (eg, psychosis, depression) (11,12); impaired school (13), work (14) and driving performance (15); increased sexual risk taking and sexually transmitted infections (16); respiratory disease (17); cancer (18); myocardial infarction (19); and immune impairment (20). The therapeutic benefit of cannabinoid therapy has largely been confined to the symptomatic relief of nausea, anorexia and pain (21).

Few studies have explored cannabis use among individuals in Canada living with HIV/AIDS $(8,9,22,23)$. These studies have suggested that cannabis use is approximately two- to threefold more prevalent among individuals living with HIV/AIDS compared with the general population. The principal indications for medicinal marijuana identified in these studies have included anorexia, nausea, pain and stress. Perceived and actual adverse consequences of cannabis in this population have not been thoroughly explored.

The aims of the present exploratory study were to measure the prevalence of self-reported recreational and medicinal cannabis use, perceived benefits and adverse consequences associated with cannabis use, as well as to assess the predictors of cannabis use among HIV patients in Maritime Canada. Such research does not exist for the region. Providing care for individuals living with HIV in Maritime Canada can be a challenge due to the sociodemographic characteristics of the region such as its highly rural nature, long commutes for health services for many patients, few resources, high poverty rates and stigma/discrimination associated with HIV infection. Maritime Canada represents a unique Canadian population, making such research critically important. The current study measured several psychological variables (eg, hopelessness, depression, self-efficacy) as well as high-risk behaviours and additional drug use to assess a wide range of novel predictors of cannabis use among this patient population. A cross-sectional survey was performed in the two largest clinics serving individuals with HIV infection in this region.

\section{METHODS}

\section{Definition of medicinal cannabis}

The Canadian Senate Report on Cannabis Use notes that medicinal cannabis is used to achieve a therapeutic impact on a specified medical problem, and Health Canada, through their Marijuana Medical Access Regulations, outlines specific conditions for which medicinal cannabis use could be appropriate (6). For the current study, medicinal cannabis use was broadly defined as participants' self-reported use of cannabis for medicinal purposes. The overlap between recreational and medicinal consumption makes it difficult to differentiate between these types of use. Nevertheless, such distinctions are important and, thus, were pursued in the current study.

\section{Study design}

Data were collected at two Maritime hospital immunodeficiency clinics. Site 1 recruited 80 participants and site 2 recruited 151 participants. Five participants were subsequently removed from data analysis because they did not indicate whether they used cannabis $(n=226)$.
Data collection procedures were consistent between sites. A clinic staff member approached potential participants with study information during regular scheduled clinic visits. Individuals who expressed interest in the study met a member of the research team to further discuss the study and provide informed consent. Following informed consent, participants completed several questionnaires (see Measures section) while waiting to be seen by clinic staff. On completion, participants sealed the questionnaires in an envelope. Participants' CD4 counts and viral load levels for the preceding year were sealed in the same envelope. Forms contained no personal identification.

All patients attending the hospital clinics over a six-month period who met inclusion criteria were invited to participate. Inclusion criteria included: living with HIV or AIDS; being a patient at one of the HIV clinics in the study; and being $\geq 19$ years of age. Exclusion criteria included: being an inmate at a correctional facility; and not being able to read English. Ethics approval was obtained from South East Regional Health Authority, New Brunswick; Capital District Health Authority, Nova Scotia; and Memorial University, St John's, Newfoundland and Labrador.

\section{Data analysis}

Measures of central tendency, dispersion, frequency counts and proportions were used to describe study variables. $\chi^{2}$ and independentsamples $t$ tests were used to assess univariate relationships between potential predictor variables and cannabis use. Binary logistic regression was subsequently used to examine the impact of preidentified significant predictor variables (through univariate analyses) in the prediction of cannabis use.

\section{Measures}

General HIV questionnaire: This measure assessed demographic variables (eg, age, length of time living with HIV or AIDS, education level) as well as cannabis use, medication adherence, high-risk behaviour(s) and symptoms associated with HIV/AIDS.

The questionnaire collected information on the following variables: cannabis use (eg, Do you use medicinal marijuana?, Do you use marijuana other than medicinal marijuana?); frequency and quantity of cannabis use (eg, financial cost and weight used over specific time periods); reasons for cannabis use and level of effectiveness of cannabis for identified purposes of use; negative consequences of cannabis use; HIV medication adherence; nature, frequency and severity of high-risk behaviour(s); reasons for high-risk behaviour(s); other drug, alcohol or tobacco use; nature and frequency of symptoms associated with HIV/AIDS; and the degree to which HIV/AIDS had impacted the participant. Most variables were measured through nominal data (eg, lists of reasons or symptoms that could be checked) or ordinal data (eg, rank order from high to low or low to high such as symptom severity questions), with some measuring ratio data (eg, weight/cost questions for cannabis use).

The general HIV questionnaire was developed by members of the research team and health care professionals with expertise in HIV (eg, HIV physician, HIV nurse). The final measure was piloted for clarity and readability using a small group of individuals who were not living with HIV.

Self-efficacy: A brief self-report inventory measuring general selfefficacy was used. It contained 10 items with a Likert scale ranging from 0 ("not at all true") to 4 ("exactly true"). It has been used in $>1000$ research studies and exhibits satisfactory reliability and validity (24). Reliability was assessed in the current study using Cronbach's $\alpha$ and was determined to be high at both research sites $(\alpha=0.93 ; 0.92)$.

Beck Hopelessness Scale: The Beck Hopelessness Scale (BHS) (25) is a widely used instrument for assessing negative expectations for the future. The scale has been used to detect hopelessness and pessimism among various populations. The BHS has 20 true and false statements regarding negative expectations about the future. Scores can range from 0 to 20. There is also a symptom severity index: 0 to $3=$ asymptomatic, 4 to $8=$ mild, 9 to $14=$ moderate, and $>14=$ severe. The test has been demonstrated to exhibit high validity and reliability (25). Inter-rater reliability for the BHS has also been demonstrated to be high $(r=0.93)(25)$. 


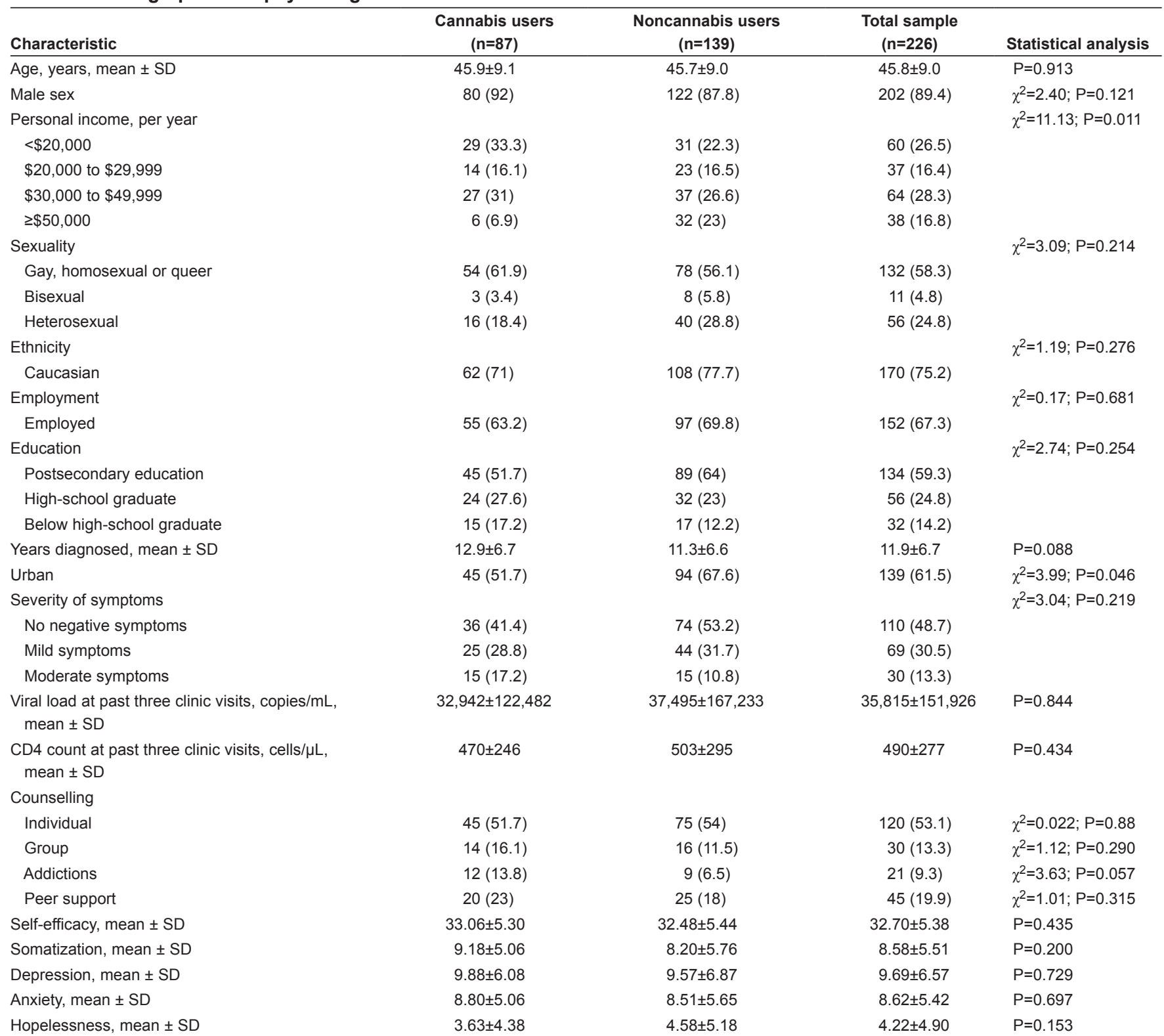

Data presented as $n$ (\%) unless otherwise indicated. Not all participants provided data for each variable category; percentages and frequencies represent participantreported data based on subgroups and overall sample size

Brief Symptom Inventory 18: This is a brief self-report inventory designed to assess psychological distress and potential psychiatric disorders in medical and community populations (26). The Brief Symptom Inventory 18 was used in the current study to assess somatization, depression and anxiety. There are 18 questions, each containing a Likert scale ranging from 0 to 4 , where $0=$ "not at all" and $4=$ "extremely". The Brief Symptom Inventory 18 has been used with an HIV population in previous research and has satisfactory internal consistency $(0.79$ to 0.84$)$ as well as convergent validity with similar measures (0.93 to 0.96) (26). In the current study, reliabilities were as follows: somatization $(\alpha=0.99 ; 0.86)$, depression $(\alpha=1.0 ; 0.91)$ and anxiety $(\alpha=0.99 ; 0.84)$.

\section{RESULTS}

Demographic and psychological variables (Table 1)

A total of 256 patients were invited to enroll in the study and $231(90 \%)$ agreed to participate. Five participants were removed from the analyses because they did not indicate cannabis or noncannabis use, resulting in a sample size of 226 . The mean ( \pm SD) age of participants was $45.8 \pm 9.0$ years. Participants reported living with HIV for an average of $11.9 \pm 6.7$ years. Overall, symptom severity was mild, with $79.2 \%$ (179 of 226) of the sample reporting mild to no negative impacts from HIV. The participants' sex was predominately male (202 of 226 [89.4\%]), with 22 females and one transgender participant. Having a college/university education was reported by $59.3 \%$ (134 of 226) of the total sample and an additional 24.8\% (56 of 226) reported completing high school. The majority of study participants resided in urban centres (139 of 226 [61.5\%]). Cannabis use was significantly associated with lower income level and rural residence by univariate analysis.

\section{Cannabis use}

Current use of cannabis was reported by 38.5\% (87 of 226) of study participants. When asked specifically whether medicinal cannabis was used, 21.8\% (19 of 87) of the total cannabis-using sample reported medicinal use. Only 2.3\% (two of 87 ) of the cannabis using participants 


\begin{tabular}{|c|c|c|c|c|c|}
\hline \multirow[b]{2}{*}{$\begin{array}{l}\text { Reasons for } \\
\text { cannabis use }^{*}\end{array}$} & \multicolumn{5}{|c|}{ Reported effectiveness $^{\dagger}$} \\
\hline & $\begin{array}{c}\text { Not } \\
\text { helpful }\end{array}$ & $\begin{array}{l}\text { Somewhat } \\
\text { not helpful }\end{array}$ & $\begin{array}{l}\text { Not } \\
\text { Sure }\end{array}$ & $\begin{array}{c}\text { Somewhat } \\
\text { helpful }\end{array}$ & $\begin{array}{l}\text { Very } \\
\text { helpful }\end{array}$ \\
\hline Anxiety $(n=41)$ & 1 & 1 & 1 & 14 & 21 \\
\hline Stress $(n=51)$ & 1 & 1 & 1 & 15 & 28 \\
\hline Physical pain (n=32) & 0 & 0 & 1 & 12 & 16 \\
\hline Depression $(n=33)$ & 0 & 1 & 2 & 12 & 12 \\
\hline $\begin{array}{l}\text { Appetite stimulation } \\
(\mathrm{n}=46)\end{array}$ & 0 & 0 & 0 & 4 & 37 \\
\hline Nausea $(n=28)$ & 0 & 0 & 0 & 6 & 18 \\
\hline Pleasure $(n=61)$ & 1 & 1 & 4 & 26 & 21 \\
\hline Party $(n=32)$ & 1 & 0 & 3 & 12 & 13 \\
\hline Tremor $(n=6)$ & 1 & 0 & 1 & 2 & 2 \\
\hline Weakness $(n=8)$ & 1 & 1 & 0 & 2 & 4 \\
\hline Tiredness $(n=12)$ & 0 & 1 & 1 & 4 & 4 \\
\hline Vision problems $(n=3)$ & 0 & 1 & 0 & 2 & 0 \\
\hline Slurred speech $(n=0)$ & 0 & 0 & 0 & 0 & 0 \\
\hline Memory loss $(n=1)$ & 1 & 0 & 0 & 0 & 0 \\
\hline Constipation (n=2) & 0 & 0 & 0 & 0 & 2 \\
\hline Headaches $(n=18)$ & 1 & 0 & 0 & 6 & 7 \\
\hline Diarrhea $(n=6)$ & 1 & 0 & 2 & 1 & 3 \\
\hline Tingling/numbness $(n=14)$ & 0 & 0 & 1 & 6 & 6 \\
\hline
\end{tabular}

${ }^{*} n=$ number of participants reporting marijuana use for each reason for use; tNot all participants provided data on 'Reported effectiveness'; therefore, reported effectiveness frequency counts do not equal $n$ size for corresponding reason for cannabis use

reported exclusively using medicinal cannabis. However, when participants' reasons for cannabis use were explored, only $8.1 \%$ (seven of 87 ) of the cannabis-using participants omitted medically related symptoms as reasons for use and instead chose 'pleasure' or 'partying' categories as reasons for use. Ten of the cannabis-using participants left the 'reasons for use' questions blank. Thus, $80.5 \%$ (70 of 87 ) of the cannabis-using participants reported a symptom-relieving benefit (eg, stress, anxiety, depression, anorexia). Nearly the entire cannabis-using sample (85 of 87 [97.7\%]) also reported recreational cannabis use.

Participants reported using an average of $18.3 \pm 21.1 \mathrm{~g}(\mathrm{n}=70)$ of cannabis in a typical month (median $14.5 \mathrm{~g}$; quartiles $4.0 \mathrm{~g}, 25 \mathrm{~g}$ ). Four participants reported consuming $\geq 60 \mathrm{~g}$ of cannabis in a typical month. With these four participants removed from the analysis, the average amount of cannabis consumed by participants in a typical month was $14.4 \pm 12.3 \mathrm{~g}(\mathrm{n}=66)$. Participants spent an average of $\$ 105.15 \pm 109.87$ on cannabis in a typical month (median $\$ 60.00$, mode $\$ 0.00$, range $\$ 0$ to $\$ 425.00 ; n=81$ ). Participants had used cannabis for an average of $22.4 \pm 10.7$ years $(n=83)$, making the average age of use initiation $23.3 \pm 9.5$ years $(n=82)$. Forty participants reported no change in their cannabis use following diagnosis of HIV, whereas 21 participants reported reduced use following diagnosis and 17 participants reported increased use following diagnosis.

Reasons for cannabis use

Consumption for pleasure (ie, euphoriant effect) was the most common reason identified for cannabis use (Table 2). Other reasons included relief of anxiety, stress, physical pain, depression, nausea and appetite stimulation. Participants' self-reported effectiveness of cannabis tended to fall in the 'somewhat helpful' to 'very helpful' range for relief of anxiety, stress, physical pain, depression, nausea, appetite stimulation, and facilitation of pleasure and partying.

Consequences of cannabis use

Some participants also noted negative consequences with cannabis use (Figure 1). Pertinent negative consequences included problems at

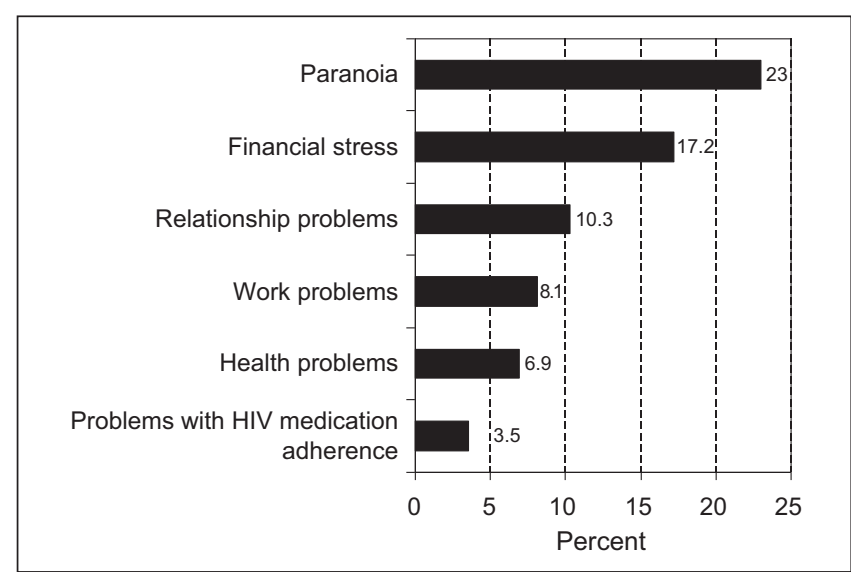

Figure 1) Reported negative consequences due to cannabis use $(n=87)$

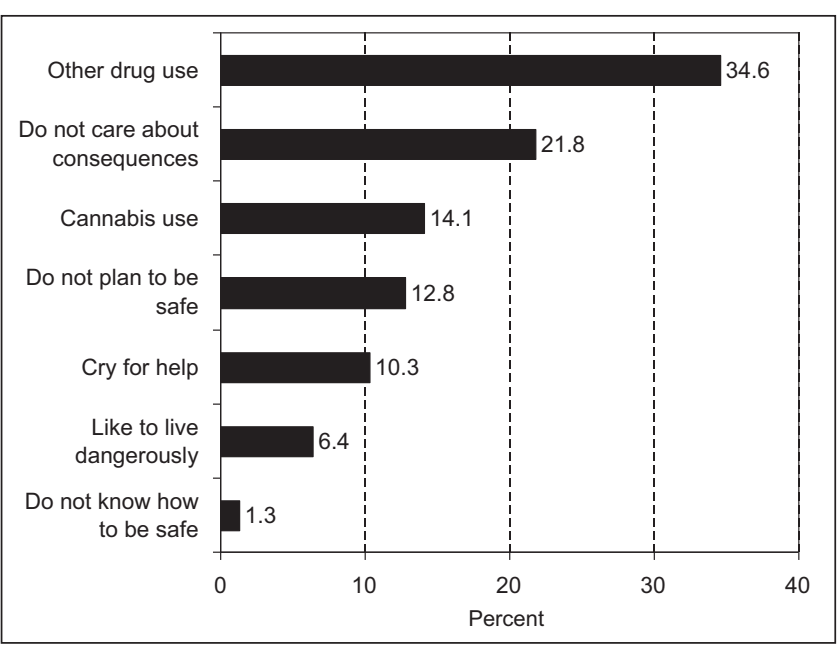

Figure 2) Core reasons for high-risk activity

work, financial stress, health issues, relationship problems and paranoia. Three participants were of the opinion that their cannabis use interfered with adherence to antiretroviral medication.

High-risk activity

Overall, $34.5 \%(n=78)$ of participants reported engaging in at least one type of high-risk activity, ranging from unsafe sexual practices to unhealthy eating (Table 3). The range of personal and/or societal impacts of these high-risk activities would certainly vary. Nonetheless, participants themselves labelled all of these behaviours/activities as 'high-risk'. The most prevalent reported high-risk activity was cognitively orientated (ie, suicidal thoughts), with fewer participants reporting a translation into suicidal behaviour. Unsafe sexual practices and driving under the influence were the most commonly cited categories with direct risk for both participants and society at large. Participants noted several reasons for high-risk activity (Figure 2). 'Other drug use' and 'not caring about the consequences' were the most commonly cited reasons reported by participants for their engagement in high-risk activity. Cannabis use was noted as a reason for engaging in high-risk activities by $14.1 \%$ ( 11 of 78 ) of the high-risk activity group.

There was a significant difference noted between the cannabisusing and non-cannabis-using groups for the 'driving under the influence of a substance' category, with the cannabis-using group reporting higher levels of this activity $\left(\chi^{2}=5.33 ; \mathrm{P}=0.021\right)$. When individual types of 'other drug use' were explored, the cannabis-using group was more likely to report using ecstasy $\left(\chi^{2}=5.71 ; \mathrm{P}=0.017\right)$ and tobacco $\left(\chi^{2}=15.32 ; P=0.001\right)$. 
TABLE 3

Self-reported high-risk activity and other substance use

\begin{tabular}{|c|c|c|c|c|}
\hline & $\begin{array}{c}\text { Cannabis users } \\
(n=87)\end{array}$ & $\begin{array}{c}\text { Non-cannabis users } \\
(n=139)\end{array}$ & $\begin{array}{c}\text { Total sample } \\
(n=226)\end{array}$ & Statistical analysis \\
\hline Suicidal behaviour & $2(2.3)$ & $7(5)$ & $9(4)$ & $\chi^{2}=0.46 ; P=0.500$ \\
\hline Driving under the influence of a substance & $11(12.6)$ & $6(4.3)$ & $17(7.5)$ & $\chi^{2}=5.33 ; P=0.021$ \\
\hline Unsafe sexual practices & $14(16.1)$ & $18(12.9)$ & $32(14.2)$ & $\chi^{2}=0.41 ; P=0.524$ \\
\hline HIV medication nonadherence & $8(9.2)$ & $16(11.5)$ & $24(10.6)$ & $\chi^{2}=0.30 ; P=0.582$ \\
\hline Cocaine use & $6(6.9)$ & $8(5.8)$ & $14(6.2)$ & $\chi^{2}=0.14 ; P=0.712$ \\
\hline Acid use & $3(3.4)$ & $0(0)$ & $3(1.3)$ & $\chi^{2}=2.62 ; P=0.105$ \\
\hline Ecstasy use & $9(10.3)$ & $3(2.2)$ & $12(5.3)$ & $\chi^{2}=5.71 ; P=0.017$ \\
\hline Alcohol use & $41(47.1)$ & $49(35.3)$ & $90(39.8)$ & $\chi^{2}=3.42 ; P=0.065$ \\
\hline Tobacco use (smoking) & $50(57.5)$ & $44(31.7)$ & $94(41.6)$ & $\chi^{2}=15.32 ; P=0.001$ \\
\hline Number of cigarettes per day, mean \pm SD & $13.9 \pm 9.7$ & $9.1 \pm 11.7$ & $11.0 \pm 11.2$ & $P=0.012$ \\
\hline
\end{tabular}

Data presented as $n(\%)$ unless otherwise indicated

TABLE 4

Variables in the regression equation

\begin{tabular}{|c|c|c|c|c|c|c|c|}
\hline Predictors & B & SE & Wald & df & $\mathbf{P}$ & $\operatorname{Exp}(B)$ & $95 \% \mathrm{Cl}$ \\
\hline Geographical (rural versus urban) & 0.44 & 0.34 & 1.72 & 1 & 0.190 & 1.56 & $0.80-3.01$ \\
\hline Income, per year & & & 7.98 & 3 & 0.046 & & \\
\hline$>\$ 50,000$ & 1.55 & 0.57 & 7.40 & 1 & 0.007 & 4.71 & $1.54-14.40$ \\
\hline$\$ 20,000$ to $\$ 29,999$ & 0.41 & 0.46 & 0.79 & 1 & 0.375 & 1.50 & $0.61-3.67$ \\
\hline Smoking cigarettes & -0.88 & 0.32 & 7.43 & 1 & 0.006 & 0.41 & $0.22-0.78$ \\
\hline Ecstasy use & -1.72 & 0.73 & 5.47 & 1 & 0.019 & 0.18 & $0.04-0.76$ \\
\hline
\end{tabular}

Demographic characteristics, high-risk activity and substance use associated with cannabis use

The predictive power of significant variables identified through univariate analyses were explored using a logistic regression model with cannabis use as the criterion variable. The overall model was significant $\left(\chi^{2}=31.37\right.$ [7], $\left.\mathrm{P}<0.001, \mathrm{R}^{2}=0.20\right)$ with an overall classification accuracy rate of $69.9 \%$. For the predictor variables, lower income $\left(\chi^{2}=7.98\right.$; $\mathrm{P}=0.046)$, ecstasy use $\left(\chi^{2}=5.47 ; \mathrm{P}=0.019\right)$ and smoking tobacco $\left(\chi^{2}=7.43 ; \mathrm{P}=0.006\right)$ were significant predictors of cannabis use (Table 4$)$. Income was entered into the model as a categorical variable.

\section{DISCUSSION}

Previous Canadian research has suggested that cannabis use is common among HIV-positive cohorts in Central and Western Canada $(9,23)$. The current study found that $38.5 \%$ of participants were current users of cannabis. This prevalence of cannabis use is similar to HIV populations in other Canadian regions (23) and is at least 3.5-fold higher than in the general population 35 to 55 years of age (4). There was a large range of reported cannabis consumption among participants in the present study. A recent study by Belle-Isle and Hathaway (8) also noted a wide range in the amount of cannabis consumed, with an average consumption of $66 \mathrm{~g}$ of cannabis per month compared with 18.3 g per month in the present study. Participants in the Belle-Isle and Hathaway (8) study were predominately white males, had been living with HIV for an average of 10 years, and mainly resided in Ontario, British Columbia and Quebec. Both the Belle-Isle and Hathaway (8) study and the current study have also documented that cannabis use in HIV-infected cohorts is associated with significant financial expenditure. Despite the significant cost of cannabis, current users had lower income levels than nonusers. Furler et al (9) had previously reported that lower socioeconomic level was associated with medicinal marijuana use in an Ontario HIV-positive cohort. Recreational cannabis consumption in early adolescence has also been associated with lower socioeconomic level (27). Our results are typical of other studies performed outside of Canada in terms of use quantity and monthly cost (28).

Although the route of cannabis attainment was not explored in our questionnaire, previous research in Canadian HIV-positive cohorts have shown that cannabis is usually obtained from illegal sources $(8,9)$. Some participants in the current study reported spending very little money on cannabis, raising important future research questions surrounding routes of attainment (eg, through friends/family, personal growing through a license to produce) and potential barriers to legal access.

A higher prevalence of cannabis use by rural versus urban residents was observed. Previous research in Canada has documented high rates of cannabis use among young males residing in rural environments (29). This was not a predictor of cannabis use according to the regression analysis, in which income level was retained as a significant association.

Most study participants reported a long history of cannabis use, often preceding the HIV diagnosis itself, highlighting cannabis use as a long-term behaviour. The level of cannabis consumption did not change significantly for many study participants following the diagnosis of HIV infection.

Formulating an objective definition of 'medicinal cannabis' poses a significant precisional challenge, given that large cross-sectional studies indicate that it is consumed principally for its mood-altering properties rather than for relief of medical symptoms. Recreational use was common in our current study sample, in which cannabis use appears to have been a long-standing practice. We defined medicinal cannabis according to the study participants' opinions, recognizing that such a definition would be highly subjective. The use of prescribed cannabis subsequent to the diagnosis of HIV infection would be a more precise definition of medicinal cannabis use, but route of cannabis ascertainment was not explored in the present study. According to our definition, 21.8\% (19 of 87 ) of participants reported using medicinal cannabis. Almost the entire population used cannabis for recreational 
purposes, while a large proportion $(80.5 \% ; 70$ of 87 ) acknowledged some symptom benefit.

Thus, $8.4 \%$ (19 of 226) of our study sample were using cannabis that they defined as medicinal cannabis, although only two participants reported using it exclusively for medicinal purposes. This is similar to a large British Columbia survey of HIV-positive individuals, which found that $14 \%$ were current users of medicinal marijuana (22). These statistics highlight the intrinsic ambiguity of defining medicinal cannabis in this population, in which a large proportion of users use cannabis for recreational purposes, with the additional acknowledgment of medicinal benefits. This ambiguity could pose a significant barrier for prescribers. Recreational use may be a partial explanation for why most cannabis in the HIV-positive population, as in the Canadian population at large, is obtained from illegal sources $(8,9)$. This being said, more research is needed to understand local and systemic barriers to legal access.

The self-reported medicinal benefits of cannabis use among study participants were consistent with published research $(8,9,22,23,30,31)$. The most commonly reported reasons for use included stimulation of appetite, relief of anxiety and stress, and alleviation of pain. The only approved synthetic cannabinoid in Canada for HIV/AIDS is dronabinol, indicated for anorexia associated with weight loss. Four clinical trials assessing its use for anorexia in HIV/AIDS have been published (32-35). Some of these trials have documented an orexigenic benefit, but there is currently insufficient evidence to document an impact on weight. Dronabinol was compared with smoked marijuana in one trial, with no evidence of therapeutic advantage (33).

Numerous studies have documented high rates of emotional distress and depression in HIV-positive patients undergoing treatment $(36,37)$. Although our participants reported improvement in stress and anxiety with cannabis, there is always the risk that such effects may be short-term in nature, given cannabis's euphoriant effect. As well, given the growing evidence for an association between cannabis and depression, anxiety, psychosis and amotivational state $(11,19,38)$, any such benefits derived from cannabis use need to be weighed against potential risks. Further controlled research is needed to assess any potential benefits or harms of cannabis use for such cognitiveaffective conditions, especially given the high degree of self-reported benefit among participants in the current study.

A large proportion of cannabis users in our study reported the alleviation of pain as a benefit. One randomized, crossover trial comparing smoked cannabis to placebo for neuropathic pain in HIV documented greater pain relief in the treatment arm (39).

Negative consequences of cannabis use were less commonly reported compared with self-reported benefits of cannabis use. The more common reported consequences included "financial stress" and "feeling paranoid". Paranoia was a noted consequence of cannabis use by $26 \%$ of HIV-positive participants in a study by Ware et al (23), which is similar to the findings in the current study. Work-related problems were reported by $8.1 \%$ (seven of 87 ) of cannabis users. Research has highlighted that heavy cannabis use can have negative implications on cognitive functioning, which could adversely impact individuals in certain work situations $(14,40)$. Cannabis may adversely affect several functions involved in operation of machinery and motor vehicles (eg, balance, coordination, concentration, short-term memory) (41).

There is a paucity of research exploring cannabis use and its potential associations with high-risk behaviour among HIV populations. We identified significant relationships between cannabis use and other high-risk activities (driving under the influence of a substance and use of ecstasy and tobacco). We found no other studies reporting a relationship between cannabis use and driving under the influence among persons living with HIV/AIDS. Acute cannabis consumption is strongly associated with risk of motor vehicle collision and fatality $(15,42)$. This excess risk is dose related and amplified by the use of alcohol or other substances $(12,43)$, and could be a potential contributor to the rising proportion of accidental/violent non-AIDS-related deaths in the post-highly active antiretroviral therapy era (44).
Cannabis use was also associated with an increased use of other substances (eg, ecstasy), a finding noted in other research $(45,46)$. Tobacco and ecstasy use were two variables shown to be significant predictors through regression modelling. This lends support to cannabis prevention and treatment approaches that encompass additional substances. Smoking cessation programs are now widely advocated in the HIV-infected population, who have a significant increased cardiovascular morbidity $(47,48)$. The high concurrence of both tobacco and cannabis use in this population could potentially aggravate shared morbidities (chronic bronchitis, lung cancer, coronary disease) and diminish the success of tobacco cessation programs.

\section{Study limitations}

The current study obtained a high response rate (90\%) and included a relatively large sample size compared with previous surveys of cannabis use in the HIV-positive population. This was a predominantly Caucasian cohort with very few female study participants; therefore, findings may not be generalizable to women and non-Caucasian individuals infected with HIV. Future research involving larger samples would provide enhanced statistical power and would permit a better assessment of the subgroup using cannabis from legal sources, which were not explicitly studied. Although our survey findings are consistent with other Canadian research on HIV infection and cannabis use, the potential for participant recall bias and subjective response using this methodology is significant.

\section{CONCLUSIONS}

Cannabis use is prevalent among individuals living with HIV/AIDS in Maritime Canada, and is similar to other Canadian geographical regions. Despite describing symptom-related benefits from cannabis use, only a small proportion of patients in the present study self-identified as medicinal cannabis users. Cannabis use was characterized as a long-standing recreational behaviour, which preceded the diagnosis of HIV infection in most cases. These findings highlight the challenges surrounding both the definition and prescription of medicinal cannabis in the HIV population. While participants self-reported medicinal symptom relief from cannabis use, an association with high-risk behaviour (other substance use) was demonstrated. Adverse psychological outcomes were not identified on psychometric testing. Although Canada has more forms of prescribed or authorized medicinal cannabis than any other nation, overall prescription remains low. This paradox is not reflective of inadequate supply and deserves further research. Questions surrounding barriers to legal access need to be examined in this context.

ACKNOWLEDGEMENTS: The authors thank Ms Yvonne Lynch-Hill and Ms Gloria MacDonald for their support regarding participant access, and Ms Heather McGuire for her administrative support regarding data collection at the Capital District Health Authority research site. The authors also thank Mr Gerry White and Mr Mark Warren for their support regarding data input and analysis, and Ms Leslie Pope for her support in formatting the current manuscript. The authors acknowledge with gratitude the participation of the many HIV-infected patients at the two clinics. The authors also thank Memorial University Libraries for financial publishing support through the Open Access and Scholarly Communications Author Fund.

\section{REFERENCES}

1. Kogan N, Mechoulam R. Cannabinoids in health and disease. Dialogue S Clin Neurosci 2007;9;413-30.

2. United Nations Office on Drugs and Crime. World Drug Report 2011. United Nations Publication. 2011. <http://www.unodc.org/unodc/en/ data-and-analysis/WDR-2011.html> (Accessed March 2013).

3. United Nations Office on Drugs and Crime. World Drug Report 2007. 2007. <http://www.unodc.org/unodc/en/data-and-analysis/ WDR-2007.html> (Accessed March 2013).

4. Canadian Centre on Substance Abuse. Canadian Addiction Survey. 2004. < www.ccsa.ca/eng/priorities/research/canadianaddiction/pages/ default.aspx> (Accessed March 2013). 
5. Mechoulam R. The pharmacohistory of cannabis sativa. In: Mechoulam R, ed. Cannabinoids as therapeutic agents. Boca Raton: CRC Press, 1986:1-19.

6. Erickson B. Controlled Drugs and Substances Act-Marijuana Medical Access Regulations Registration Sor 2001-277 (JUS602460). Ottawa: Policy and Regulatory Affairs Division, 2001.

7. Health Canada. Stakeholders Statistics. Ottawa: Health Canada, 2012. <http://www.hc-sc.gc.ca/dhp-mps/marihuana/stat/index-eng. php> (Accessed March 2013).

8. Belle-Isle L, Hathaway A. Barriers to access to medical cannabis for Canadians living with HIV/AIDS. AIDS Care 2007;19:500-6.

9. Furler M, Einarson T, Millson M, Walmsley S, Bendayan R. Medicinal and recreational marijuana use by patients infected with HIV. AIDS Patient Care STDs 2004;18:215-28.

10. Wang T, Collet JP, Shapiro S, Ware M. Adverse effects of medical cannabinoids: A systematic review. CMAJ 2008;178:1669-78.

11. Bovasso G. Cannabis use as a risk factor for depressive symptoms. Am J Psychiatr 2001;158:2033-7.

12. Sewell R, Ranganathan M, D'Souza D. Cannabinoids and psychosis. Int Rev Psych 2009;21:152-62.

13. Lynsky M, Hall W. The effects of adolescent cannabis use on educational attainment: A review. Addiction 2000;95:1621-30.

14. Wadsworth E, Moss S, Simpson S, Smith A. Cannabis use, cognitive performance and mood in a sample of workers. J Psychopharmocol 2006,20:14-23.

15. Asbridge M, Hayden J, Cartwright J. Acute cannabis consumption and motor vehicle collision risk: Systematic review of observational studies and meta-analysis. BMJ 2012;344-536.

16. Smith A, Ferris J, Simpson J, Shelley J, Pitts M, Richters J. Cannabis use in sexual health. J Sex Med 2010;7(2 pt 1):787-93.

17. Tan W, Low C, Jong A, et al. Marijuana and chronic obstructive lung disease: A population-based study. CMAJ 2009;180:814-20.

18. Quoix E. What is new in the epidemiology of lung cancer: Non-smokers, women and the role of cannabis? Rev Prat 2009;59:920-24.

19. Reece A. Chronic toxicology of cannabis. Clin Toxicol (Phila) 2009;47:517-24.

20. Friedman H, Newton C, Klein T. Microbial infections, immunomodulation, and drugs of abuse. Clin Microbiol Rev 2003;16:209-19.

21. Bagshaw S, Haggen N. Medical efficacy of cannabinoids and marijuana: A comprehensive review of the literature. J Palliat Care 2002;18:111-22.

22. Braitstein P, Kendall T, Chan K, et al. Mary-jane and her patients: Sociodemographic and clinical characteristics of HIV-positive individuals using medical marijuana and antiretroviral agents. AIDS 2001;15:532-33.

23. Ware M, Rueda S, Singer J, Kilbey D. Cannabis use by persons living with HIV/AIDS: Patterns and prevalence of use. J Cannabis Therapeut 2003;3:3-15.

24. Schwarzer R, Jerusalem M. Generalized Self-Efficacy Scale. In: Weinman J, Wright S, Johnson M, eds. Measures in health psychology: A user's portfolio. Causal and control beliefs. Windsor: NFER-NELSON, 1995;35-7.

25. Beck AT, Steer RA. Beck Hopelessness Scale manual. San Antonio, Orlando: The Psychological Corporation, 1993.

26. Derogatis LR. Brief Symptom Inventory (BSI)-18. Administration, scoring and procedures manual. Minneapolis: NCS Pearson, 2011.
27. Lemstra $\mathrm{M}$, Bennett $\mathrm{N}$, Neudorf $\mathrm{C}$ et al. A meta-analysis of marijuana and alcohol use by socio-economic status in adolescents aged 10-15 years. Can J Public Health 2008;99:172-7.

28. Sidney S. Marijuana use in HIV-positive and AIDS patients: Results of anonymous mail survey. J Cannabis Therapeut 2001;1:35-41.

29. Leatherdale S, Hammond D, Kaiserman M, Rashid A. Marijuana and tobacco use among young adults in Canada: Are they smoking what they think they are smoking? Cancer Causes Control 2007;18:391-7.

30. Dansak D. Medical use of recreational drugs by AIDS patients. J Addict Dis 1997;16:25-30.

31. Prentiss D, Power R, Balmas G, Tzuang G, Israelski M. Patterns of marijuana use among patients with HIV/AIDS followed in a public health care setting. J Acquir Immune Defic Syndr 2004;35:38-45.

32. Beal J, Olson R, Laubenstein L, et al. Dronabinol as a treatment for anorexia associated with weight loss in patients with AIDS. J Pain Symptom Manage 1995;10:89-97.

33. Haney M, Rabkin J, Gunderson E, Foltin R. Dronabinol and marijuana in $\mathrm{HIV}(+)$ marijuana smokers: Acute effects on caloric intake and mood. Psychopharmacology 2005;181:170-5.

34. Struwe M, Kaempfer S, Geiger C, et al. Effect of dronabinol on nutritional status in HIV infection. Ann Pharmacother 1993;27:827-31.

35. Timpone J, Wright D, Li N, Egorin M, et al. The safety and pharmacokinetics of single-agent and combination therapy with magesterol acetate and dronabinol for the treatment of HIV wasting syndrome. AIDS Res Hum Retroviruses 1997;13:305-15.

36. Bravo P, Edwards A, Rollnick S, Elwyn G. Tough decisions faced with people living with HIV: A literature of psychosocial problems. AIDS Rev 2010;12:76-88.

37. Rabkin J. HIV and depression: 2008 review and update. Curr HIV/AIDS Rep 2008;5:163-71.

38. Sewell R, Poling J, Sofuoglu M. The effect of cannabis compared with alcohol on driving. Am J Addict 2009;18:185-93.

39. Ellis R, Toperoff W, Vaida F, et al. Smoked medicinal cannabis for neuropathic pain in HIV: A randomized crossover clinical trial. Neuropsychopharmacology 2009;34:672-80.

40. Pope H, Gruber A, Hudson J, Huestis M, Yurgelum-Todd D. Neuropsychological performance in long-term cannabis users. Archiv Gen Psychiatr 2001;58:909-15.

41. Australia's National Research Centre on AOD Workforce Development. Fact sheet 2: Cannabis and work.

42. Hall W, Degenhardt L. Adverse health effects of non-medical cannabis use. Lancet 2009;374:1383-91.

43. Blows S, Ivers R, Connor J, Ameratunga S, Woodward M, Norton R. Marijuana use in car crash injury. Addiction 2005;100:605-11.

44. Krentz H, Kliewer G, Gill M. Changing mortality rates and causes of death for HIV-infected individuals living in southern Alberta, Canada from 1984-2003. HIV Med 2005;6:99-106.

45. Brook J, Balka E, Whiteman M. The risks for late adolescence of early adolescent marijuana use. Am J Public Health 1999;89:1549-54.

46. Wu L, Pilowsky D, Schlenger W. High prevalence of substance use disorders among adolescents who use marijuana and inhalants. Drug Alcohol Depend 2005;78:23-32.

47. Nahvi S, Cooperman N. Review: The need for smoking cessation among HIV-positive smokers. AIDS Educ Prev 2009;21(3 Suppl):14-27.

48. Rahmanian S, Wewers M, Koleta S, Reynolds, N, Ferketich A, Diaz P. Cigarette smoking in the HIV-infected population. Proc Am Thorac Soc 2011;8:313-90. 


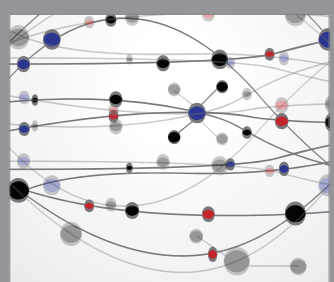

The Scientific World Journal
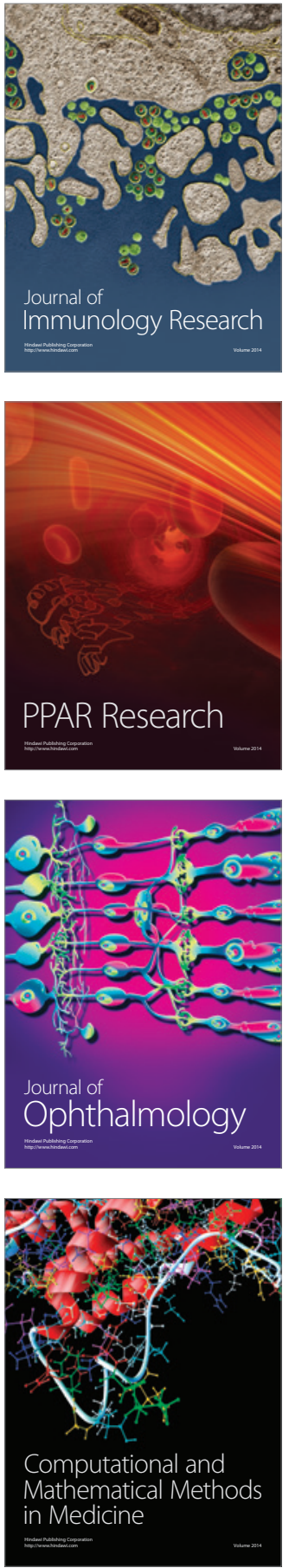

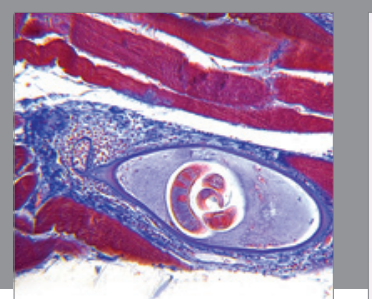

Gastroenterology Research and Practice

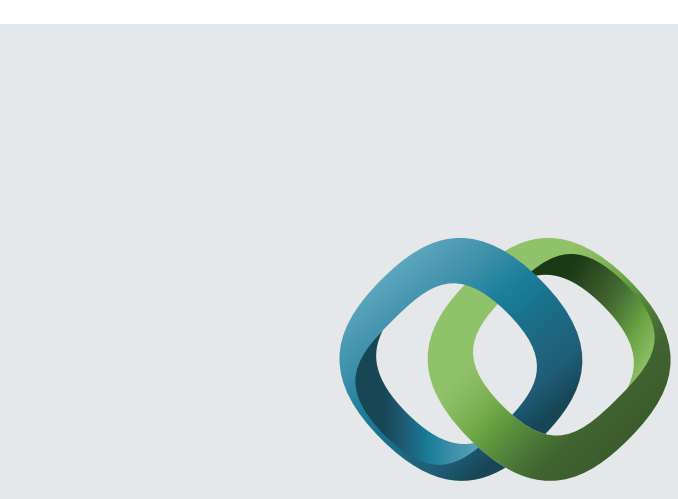

\section{Hindawi}

Submit your manuscripts at

http://www.hindawi.com
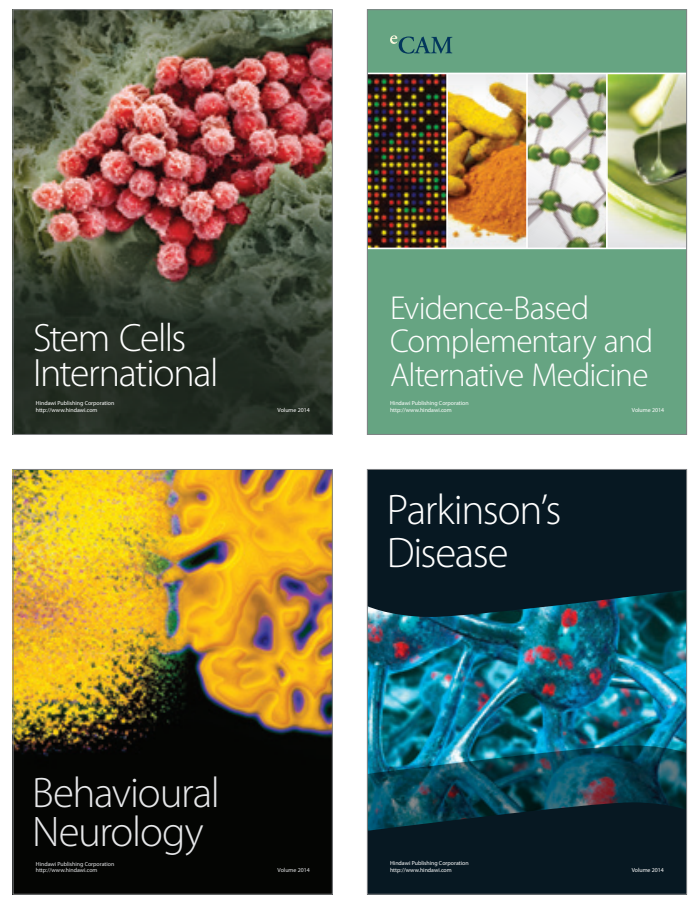
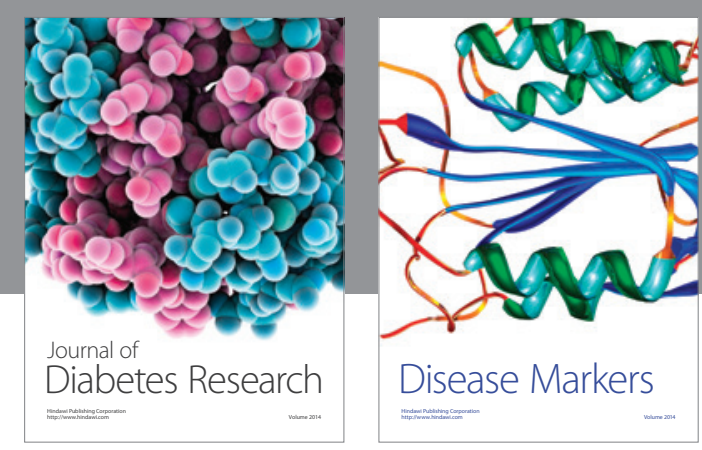

Disease Markers
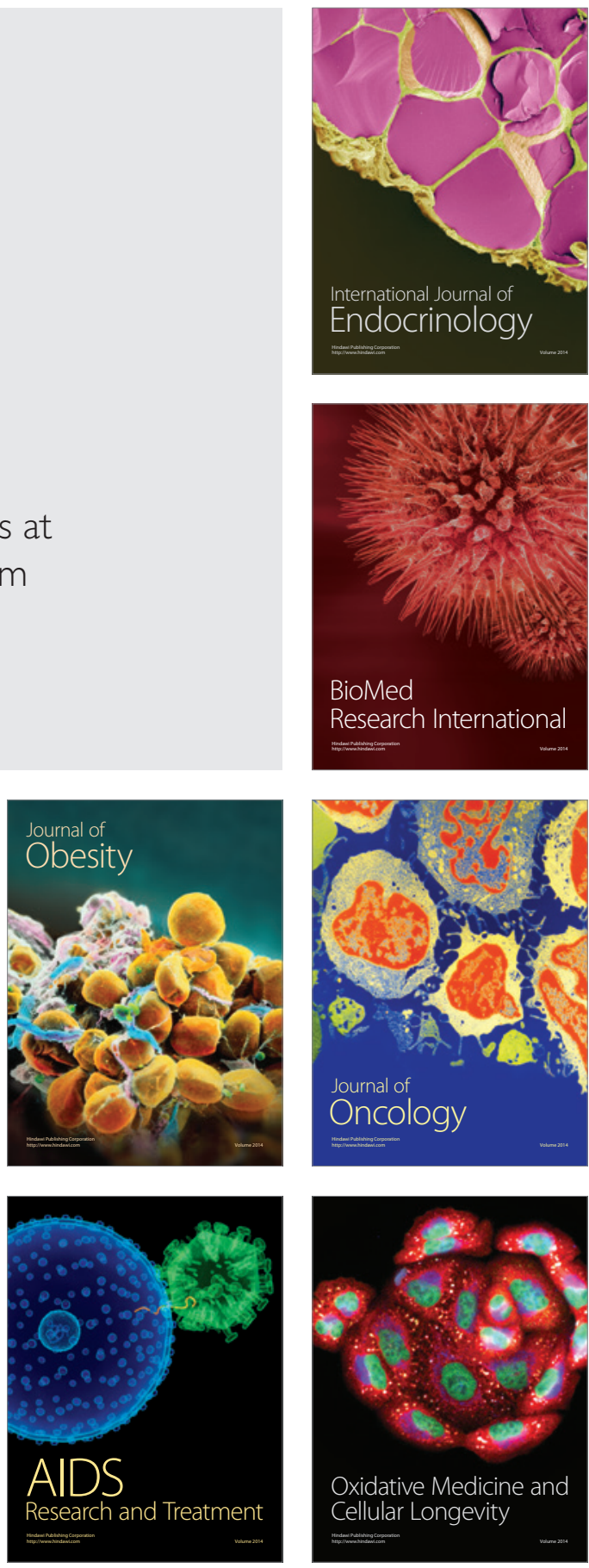